\title{
Interactive effects of phosphorus deficiency and exogenous auxin on root morphological and physiological traits in white lupin (Lupinus albus L.)
}

\author{
TANG HongLiang ${ }^{1,2}$, SHEN JianBo $^{1 *}$, ZHANG FuSuo $^{1} \&$ RENGEL Zed ${ }^{3}$ \\ ${ }^{1}$ Centre for Resources, Environment and Food Security, Department of Plant Nutrition, Key Laboratory of Plant-Soil Interactions, Ministry of \\ Education, China Agricultural University, Beijing 100193, China; \\ ${ }^{2}$ College of Life Science, Hebei University, Baoding 071002, China; \\ ${ }^{3}$ Soil Science \& Plant Nutrition, School of Earth and Environment, The University of Western Australia, Crawley WA 6009, Australia
}

Received August 14, 2012; accepted December 11, 2012; published online March 15, 2013

\begin{abstract}
White lupin (Lupinus albus) exhibits strong root morphological and physiological responses to phosphorus (P) deficiency and auxin treatments, but the interactive effects of $\mathrm{P}$ and auxin in regulating root morphological and physiological traits are not fully understood. This study aimed to assess white lupin root traits as influenced by $\mathrm{P}\left(0\right.$ or $\left.250 \mu \mathrm{mol} \mathrm{L} \mathrm{L}^{-1}\right)$ and auxin $\left(10^{-8}\right.$ mol $\mathrm{L}^{-1}$ NAA) in nutrient solution. Both P deficiency and auxin treatments significantly altered root morphological traits, as evidenced by reduced taproot length, increased number and density of first-order lateral roots, and enhanced cluster-root formation. Changes in root physiological traits were also observed, i.e., increased proton, citrate, and acid phosphatase exudation. Exogenous auxin enhanced root responses and sensitivity to $\mathrm{P}$ deficiency. A significant interplay exists between $\mathrm{P}$ and auxin in the regulation of root morphological and physiological traits. Principal component analysis showed that $\mathrm{P}$ availability explained $64.8 \%$ and auxin addition $21.3 \%$ of the total variation in root trait parameters, indicating that $\mathrm{P}$ availability is much more important than auxin in modifying root responses of white lupin. This suggests that white lupin can coordinate root morphological and physiological responses to enhance acquisition of $\mathrm{P}$ resources, with an optimal trade-off between root morphological and physiological traits regulated by external stimuli such as $\mathrm{P}$ availability and auxin.
\end{abstract}

cluster root, carboxylate exudation, proton, auxin, phosphorus deficiency, Lupinus albus

Citation: Tang H L, Shen J B, Zhang F S, et al. Interactive effects of phosphorus deficiency and exogenous auxin on root morphological and physiological traits in white lupin (Lupinus albus L.). Sci China Life Sci, 2013, 56: 313-323, doi: 10.1007/s11427-013-4461-9

Phosphorus (P), an essential nutrient in plants [1], is involved in the regulation of many biochemical and physiological processes [2]. Although the total amount of $\mathrm{P}$ in soil may be high, most soil $\mathrm{P}$ is present in unavailable forms [3]. In acidic soils where $\mathrm{P}$ is fixed to $\mathrm{Al}$ and $\mathrm{Fe}$ oxides and hydroxides, and in calcareous soils where $\mathrm{P}$ is precipitated as calcium phosphates, low $\mathrm{P}$ availability limits crop production $[4,5]$.

Plants have evolved a series of adaptive strategies to im-

*Corresponding author (email: jbshen@ cau.edu.cn) prove $\mathrm{P}$ acquisition. These strategies include the secretion of root exudates, alteration of root morphology and architecture, and formation of symbiotic associations with mycorrhizal fungi [2,6]. Plants can stimulate root proliferation (a morphological change) and/or increase P-uptake rates (a physiological change) to exploit spatial and temporal heterogeneity in nutrient resources [7].

Many attempts have been made to examine root response to $\mathrm{P}$ availability by measuring root length, lateral root (LR) density, root hair elongation, biomass allocation, root exudates, and acid phosphatase activity. Plant responses to low 
$\mathrm{P}$ availability are associated with increased resource allocation to roots $[8,9]$, which leads to increased root: shoot ratios and enhanced P acquisition [10,11]. Roots also exhibit morphological responses to low $\mathrm{P}$ availability, such as increases in specific root length [12], root hair density and elongation [13,14], and LR formation and elongation [15]. These plastic root responses increase the surface area to volume ratio [16] and enable plants to capture $\mathrm{P}$ from P-limited environments or P-rich patches in otherwise P-deficient soils [17-19].

Root physiology is also important during nutrient capture [20-22]. The physiological responses influencing $\mathrm{P}$ acquisition include proton release $[5,23]$ as well as exudation of carboxylates [5] and phosphatases [24]. Some plants have developed specialized root structures, called cluster roots (CRs), in response to low $\mathrm{P}$ availability [25-29]. In white lupin, CR formation increases $\mathrm{P}$ uptake by expanding root surface area and enhancing exudation of protons, carboxylates, and phosphatases [30-33], which can efficiently mobilize $\mathrm{P}$ from mineral-bound or organic $\mathrm{P}$ fractions in soil. Collectively, root morphological and physiological responses can be regulated by low $\mathrm{P}$ availability or P-rich patches in otherwise low-P soils.

Auxin plays a crucial role in mediating P-starvation effects on root-hair elongation and LR initiation in Arabidopsis [34] and CR formation in white lupin [35,36]. Phosphorus-deficient Arabidopsis plants can form more LRs than P-sufficient plants when exposed to exogenous auxin [34]. The addition of auxin to P-sufficient white lupin plants enhances CR formation to a larger extent than in P-deficient plants [35,37]. In rice, the expression of OsIPS1 and OsIPS 2 subjected to exogenous auxin and $\mathrm{P}$ starvation was about $20 \%$ higher than in plants only undergoing P starvation, suggesting an amplification effect of $\mathrm{P}$ starvation signaling by auxin [38]. Analysis of microarray gene expression data has revealed that most auxin-induced genes in rice are also up-regulated by $\mathrm{P}$ deficiency, and that a cross-talk may exist between auxin and P starvation [39]. It is thus evident that plant responses to auxin and $\mathrm{P}$ starvation are closely linked. In addition, auxin is also involved in the induction of plasma membrane (PM) $\mathrm{H}^{+}$-ATPase in wheat (Triticum aestivum L.) and soybean (Glycine max (L.) Merr.) $[23,40]$. PM H ${ }^{+}$-ATPase activation may result in acidification of the apoplast, and concomitantly, exudation of carboxylates, by hyperpolarizing the electrochemical membrane potential that drives ion transport across the plasma membrane [32,41]. Consequently, auxin alters both root morphological and physiological responses to $\mathrm{P}$ availability.

Because it exhibits strong root morphological and physiological responses when exposed to $\mathrm{P}$ deficiency, white lupin (Lupinus albus L.) has been suggested as a model experimental tool for studying root system response to $\mathrm{P}$ availability $[22,42]$. Although the effect of auxin on root morphological traits has been investigated in white lupin $[29,35,37]$, the interactive effects of $\mathrm{P}$ deficiency and auxin on root morphological and physiological traits in this species are not fully understood. The present study using white lupin aimed to: (i) examine interactive effects of $\mathrm{P}$ deficiency and exogenous auxin on root morphological and physiological traits, (ii) investigate the relative importance of $\mathrm{P}$ deficiency and exogenous auxin in modulating root morphological and physiological traits, and (iii) test whether the trade-off of root morphological versus physiological traits can be altered by differential $\mathrm{P}$ availability or auxin supply.

\section{Materials and methods}

\subsection{Plant growth}

Seeds of white lupin (L. albus L. 'Kiev Mutant') were surface-sterilized in $10 \%(\mathrm{v} / \mathrm{v}) \mathrm{H}_{2} \mathrm{O}_{2}$ for $20 \mathrm{~min}$, washed five times in deionized water, and then germinated on moist filter paper for $4 \mathrm{~d}$ at $25^{\circ} \mathrm{C}$ in the dark. Uniform seedlings were transferred, three per pot, to porcelain pots containing $2 \mathrm{~L}$ of continuously aerated nutrient solution with the following nutrient composition $\left(\mu \mathrm{mol} \mathrm{L}{ }^{-1}\right): \mathrm{Ca}\left(\mathrm{NO}_{3}\right)_{2}(2000)$, $\mathrm{K}_{2} \mathrm{SO}_{4}(700), \mathrm{MgSO}_{4}(500), \mathrm{KCl}(100), \mathrm{H}_{3} \mathrm{BO}_{3}(10), \mathrm{ZnSO}_{4}$ (0.5), $\mathrm{MnSO}_{4}(0.5), \mathrm{CuSO}_{4}(0.2),(\mathrm{NH} 4)_{6} \mathrm{Mo}_{7} \mathrm{O}_{24}(0.01)$, and ferric ethylenediaminetetraacetic acid (Fe-EDTA) (20). Phosphate was supplied as $\mathrm{KH}_{2} \mathrm{PO}_{4}$ at levels of $0 \mu \mathrm{mol} \mathrm{L} \mathrm{L}^{-1}$ $\mathrm{P}$ (P deficiency) and $250 \mu \mathrm{mol} \mathrm{L} \mathrm{L}^{-1} \mathrm{P}$ (P sufficiency) [27]. Because the action of auxin on root morphology is concentration-dependent, an experiment was conducted using various auxin concentrations $\left(10^{-6}-10^{-10} \mathrm{~mol} \mathrm{~L}^{-1}\right)$ to determine the optimal application dose. Based on our experimental evidence that $1 \times 10^{-8} \mathrm{~mol} \mathrm{~L}^{-1} \alpha$-naphthalene acetic acid (NAA) or 2,3,5-triiodobenzoic acid (TIBA) (ChemService, WestChester, PA, USA) can induce changes in root morphology without altering shoot performance (data not shown), exogenous NAA and TIBA were supplied to the nutrient solution at a concentration of $1 \times 10^{-8} \mathrm{~mol} \mathrm{~L}^{-1}$ every $3 \mathrm{~d}$ after emergence (DAE). Growth solutions were renewed every $3 \mathrm{~d}$. Plants were grown in a growth chamber with a light/dark regime of $16 / 8 \mathrm{~h}$ at $28 / 22^{\circ} \mathrm{C}$ (day/night) under $200 \mu \mathrm{mol} \mathrm{m} \mathrm{s}^{-2} \mathrm{~s}^{-1}$ light intensity and $75 \%-85 \%$ relative humidity. There were four replicates for each treatment (three plants per pot). The pots were completely randomized and re-positioned weekly to minimize environmental effects.

\subsection{Root morphology}

Taproot length was measured for each plant and the first-order LRs along the taproot axis were counted (Figure 1A). LR density was calculated by dividing the number of emerged first-order LRs by the taproot length (the number of LRs per cm taproot) [15]. Emerged and meristematic (i.e., visible under a microscope, but not yet emerged) CRs were defined as the regions with 10 or more meristems or rootlets per $\mathrm{cm}$ of first-order LRs (Figure 1B and C). The number of 

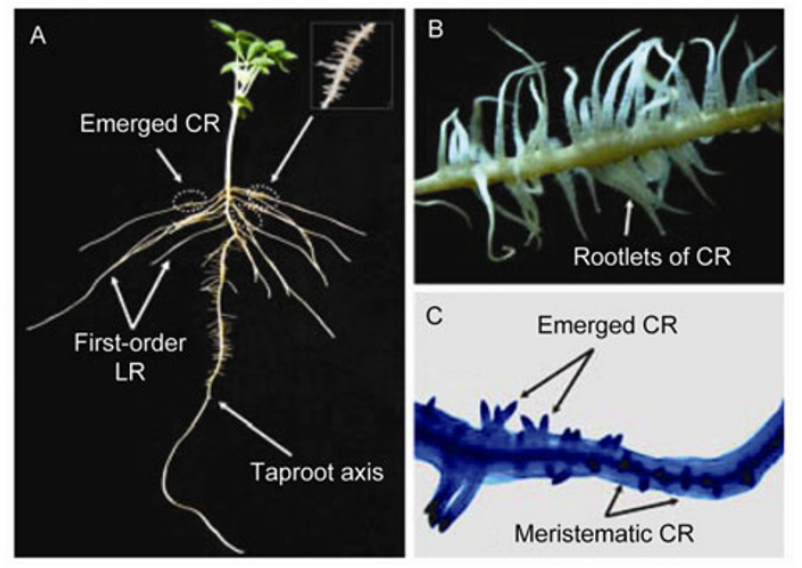

Figure 1 Root system of white lupin grown in nutrient solution under $\mathrm{P}$ deficient conditions. A, Whole plant of white lupin grown for 8 DAE under $\mathrm{P}$ deficient conditions. Arrows indicate taproot axis, first-order LRs, and emerged CRs with a single CR encircled. B, A typical CR of white lupin induced by $\mathrm{P}$ deficiency. C, P stress-induced white lupin $\mathrm{CR}$ stained with methylene blue and observed under a stereoscope.

emerged CRs was counted directly; meristematic CRs were determined with a microscope at $10 \times$ magnification after roots were fixed, cleared, and stained according to a previously-published method [43].

\subsection{Proton release}

Nutrient solution $\mathrm{pH}$ was measured using a $\mathrm{pH}$ meter and adjusted daily to 5.8 with $0.05 \mathrm{~mol} \mathrm{~L}^{-1} \mathrm{NaOH}$. The volume of $\mathrm{NaOH}$ consumed was recorded and used to calculate proton release [44].

\subsection{Collection of root exudates}

To determine whether auxin stimulates citrate exudation, two harvesting methods-from the whole root system of individual plants, or from excised cluster roots-were used to collect root exudates. In the first method, white lupin was grown at 0 or $250 \mu \mathrm{mol} \mathrm{L}-1$ P with or without the application of NAA at 3-d intervals for $15 \mathrm{DAE}$ and the entire root system was then harvested. Roots from intact plants were rinsed three times with exudate-collecting solution $\left(5 \mu \mathrm{mol} \mathrm{L}{ }^{-1} \mathrm{H}_{3} \mathrm{BO}_{3}, 600 \mu \mathrm{mol} \mathrm{L}{ }^{-1} \mathrm{CaCl}_{2}, 100 \mu \mathrm{mol} \mathrm{L}{ }^{-1} \mathrm{KCl}\right.$, and $200 \mu \mathrm{mol} \mathrm{L}{ }^{-1} \mathrm{MgCl}_{2}$ ) and then immersed in $250-\mathrm{mL}$ beakers containing $200 \mathrm{~mL}$ of continuously aerated exudatecollecting solution for $2 \mathrm{~h}$. A 10-mL sub-sample of each collecting solution was stored at $-18^{\circ} \mathrm{C}$ until analysis. In the second method, the entire root system was excised and divided into non-cluster roots (nonCRs) and CRs from both P-deficient and P-sufficient treatments. Excised nonCR and CR segments were washed thoroughly with exudatecollecting solution and incubated in $5 \mathrm{~mL}$ of exudatecollecting solution with or without NAA for $2 \mathrm{~h}$ under gentle shaking to allow release of root exudates. After collec- tion, microbial inhibitor (Micropur, Sicheres Trinkwasser, Germany, at $0.01 \mathrm{~g} \mathrm{~L}^{-1}$ ) was dropped into the solution containing root-exudates to prevent microbial degradation before measurement. The samples were subsequently stored at $-18^{\circ} \mathrm{C}$ for analysis of organic acid anions.

\subsection{Analysis of organic acid anions}

Organic acid anions in the root exudates were analyzed by high-performance liquid chromatography (HPLC) in ion suppression mode. Separation was conducted on a $250 \mathrm{~mm} \times$ $4.6 \mathrm{~mm}$ reversed-phase column (Alltima $\mathrm{C}_{18}$, Alltech Associates, Deerfield, MA, USA). The mobile phase was $25 \mathrm{mmol} \mathrm{L}^{-1} \mathrm{KH}_{2} \mathrm{PO}_{4}(\mathrm{pH} 2.25)$, with a flow rate of $1 \mathrm{~mL} \mathrm{~min}^{-1}$ at $31^{\circ} \mathrm{C}$ and $\mathrm{UV}$ detection at $214 \mathrm{~nm}$. The sample injection volume was $20 \mu \mathrm{L}$. Identification of organic acid anions was carried out by comparing retention time and absorption spectra with those of known standards [29].

\subsection{Phosphorus concentration and biomass determina- tion}

Plants were harvested at 15 DAE. Roots and shoots were dried at $70^{\circ} \mathrm{C}$ for $3 \mathrm{~d}$ and weighed. Shoots were digested in concentrated $\mathrm{H}_{2} \mathrm{O}_{2}-\mathrm{H}_{2} \mathrm{SO}_{4}$, and the $\mathrm{P}$ concentration was measured using the vanado-molybdate colorimetric method [45].

\subsection{Acid phosphatase activity at the root surface}

The activity of acid phosphatases at the root surface was measured based on published methods [46]. Excised root segments of nonCRs and CRs were transferred to 2-mL Eppendorf reaction vials and washed three times with distilled water to remove the contents of damaged cells. Washed root segments were then immersed in a solution containing $0.5 \mathrm{~mL}$ water, $0.4 \mathrm{~mL}$ of $0.2 \mathrm{~mol} \mathrm{~L}^{-1} \mathrm{Na}$-acetate buffer (pH 5.2), and $0.1 \mathrm{~mL}$ of $0.15 \mathrm{~mol} \mathrm{~L}^{-1} p$-nitrophenyl phosphate $(p \mathrm{NPP})$ substrate in acetate buffer. After reaction for $5-10 \mathrm{~min}$ at $25^{\circ} \mathrm{C}, 0.8 \mathrm{~mL}$ of the reaction medium was removed and mixed with $0.4 \mathrm{~mL}$ of $0.5 \mathrm{~mol} \mathrm{~L}^{-1} \mathrm{NaOH}$ to terminate the reaction. Absorption was measured at $405 \mathrm{~nm}$. A $p$-nitrophenol calibration curve was constructed at concentrations of $0,2,4,8,12,16$, and $20 \mu \mathrm{g} \mathrm{mL} \mathrm{m}^{-1}$. Activity was expressed as $\mu \mathrm{mol} p$-nitrophenol per g root dry weight per min.

\subsection{Statistics}

All data were analyzed using SPSS 13.0 for Windows (SPSS Inc., Chicago, IL, USA). After performing one-way analysis of variance (ANOVA), Tukey's HSD post-hoc test was used to compare differences between the means at the $5 \%$ probability level $(P \leqslant 0.05)$. Two-way ANOVA and mul- 
tivariate analysis of variance (MANOVA) were performed to test the effects of $\mathrm{P}$, auxin, and their interaction on root morphological and physiological traits.

Principal component analysis (PCA) was used to evaluate the response of root morphological and physiological traits to $\mathrm{P}$ deficiency and auxin treatment. Five root morphological variables, taproot length, number and density of the first-order LRs, and number of emerged and meristematic CRs, and five root physiological variables, proton release into the growing medium, citrate exudation by intact root systems and excised CRs, and acid phosphatase activity of nonCRs and CRs, were analyzed. The first two principal components were used to describe the relative responses of white lupin roots to $\mathrm{P}$ deficiency and auxin treatment and to calculate the total scores of root morphological or physiological variables.

\section{Results}

\subsection{Effects of $P$ deficiency and auxin treatment on bio- mass and shoot $P$ concentration}

At 15 DAE, seedlings grown at $0 \mu \mathrm{mol} \mathrm{L}{ }^{-1} \mathrm{P}$ exhibited obvious $\mathrm{P}$-deficiency symptoms, including chlorosis, necrosis, and shedding of old leaves, as well as formation of numerous CRs. Phosphorus supply had a significant effect on shoot dry weight, root dry weight, and shoot $\mathrm{P}$ concentration (Table $1, P<0.01$ ). Phosphorus deficiency decreased shoot dry weight by $37 \%-43 \%$ and root dry weight by 44\%-47\% compared with the P-sufficient treatment (Figure 2A). Auxin application had no significant influence on shoot and root dry weight (Table 1, Figure 2A). The concentration of $\mathrm{P}$ in shoots was significantly lower in P-deficient than in P-sufficient plants (Table 1, Figure 2B). The addition of auxin increased shoot $\mathrm{P}$ concentrations by
$11 \%$ for P-sufficient plants, but not for P-deficient plants. There was a significant interactive effect between $\mathrm{P}$ and auxin on shoot $\mathrm{P}$ concentration (Table 1).

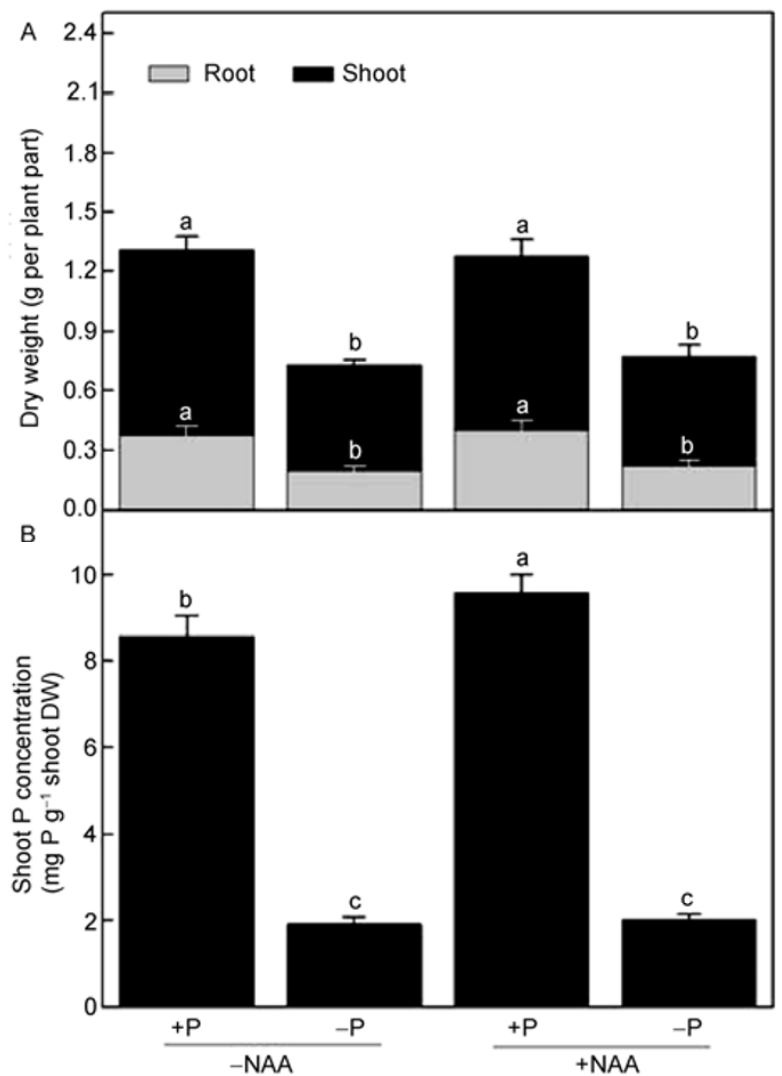

Figure 2 Effects of $\mathrm{P}$ deficiency and auxin addition on plant dry weight (A) and shoot $\mathrm{P}$ concentration (B). White lupin was cultured in 0 or 250 $\mu \mathrm{mol} \mathrm{L}{ }^{-1} \mathrm{P}$ nutrient solutions with or without the application of $10^{-8} \mathrm{~mol} \mathrm{~L}^{-1}$ NAA for 15 DAE. The data represent means \pm SE of four replicates. Different letters indicate significant differences $(P \leqslant 0.05)$.

Table 1 Results from two-way ANOVA for biomass, shoot $\mathrm{P}$ concentration, number of CRs, proton release, citrate exudation, and acid phosphatase activity as affected by $\mathrm{P}$ and auxin

\begin{tabular}{|c|c|c|c|c|c|c|c|}
\hline \multirow{2}{*}{\multicolumn{2}{|c|}{ Parameters }} & \multicolumn{2}{|c|}{$\mathrm{P}$} & \multicolumn{2}{|c|}{ Auxin } & \multicolumn{2}{|c|}{$\mathrm{P} \times$ Auxin } \\
\hline & & $F$-value & $P$-value & $F$-value & $P$-value & $F$-value & $P$-value \\
\hline \multicolumn{2}{|c|}{ Shoot dry weight } & 93.27 & $P<0.01$ & 1.88 & 0.19 & - & - \\
\hline \multicolumn{2}{|c|}{ Root dry weight } & 136.4 & $P<0.01$ & 0.36 & 0.56 & - & - \\
\hline \multicolumn{2}{|c|}{ Shoot $\mathrm{P}$ concentration } & 1700.25 & $P<0.01$ & 14.56 & $P<0.01$ & 9.138 & $P<0.01$ \\
\hline \multirow{2}{*}{ Number of CRs } & Meristematic CRs & 38.34 & $P<0.01$ & 20.28 & $P<0.01$ & 8.73 & $P<0.01$ \\
\hline & Emerged CRs & 73.92 & $P<0.01$ & 33.93 & $P<0.01$ & 0.695 & 0.42 \\
\hline \multicolumn{2}{|c|}{ Proton release rates } & 31.12 & $P<0.01$ & 35.24 & $P<0.01$ & 3.098 & 0.11 \\
\hline \multirow{3}{*}{ Citrate exudation } & Entire root system & 231.51 & $P<0.01$ & 58.03 & 0.07 & 58.03 & $P<0.01$ \\
\hline & Excised non-CRs & 42.18 & 0.68 & 112.46 & 0.15 & 42.83 & 0.24 \\
\hline & Excised CRs & 46.98 & $P<0.01$ & 125.122 & 0.04 & 46.98 & 0.115 \\
\hline $\begin{array}{l}\text { Acid phosphatase } \\
\text { activity }\end{array}$ & Non-CRs & 169.47 & $P<0.01$ & 3.85 & 0.07 & 6.34 & $P<0.05$ \\
\hline
\end{tabular}


2.2 Effects of $P$ deficiency and auxin treatment on taproot length and number and density of first-order LRs

Phosphorus deficiency reduced taproot length and increased the density of first-order LRs from 9 DAE onward, despite having no obvious effect on LR number (Figure 3A-C). The addition of auxin significantly decreased taproot length and increased the number and density of first-order LRs in P-deficient and P-sufficient plants after 6 DAE (Figure $3 \mathrm{~A}-\mathrm{C}$ ); the positive effect of auxin on number and density of first-order LRs was even more obvious under $\mathrm{P}$ deficiency than $\mathrm{P}$ sufficiency (Figure $3 \mathrm{~B}$ and $\mathrm{C}$ ). In contrast, the application of the auxin transport inhibitor TIBA reduced number and density of first-order LRs at 6 DAE and onwards, but had no significant effect on taproot length (Figure 3D-F).

\subsection{Effects of $P$ deficiency and auxin treatment on CR formation}

The results of ANOVA showed that $\mathrm{P}$ and auxin had a significant effect on the number of emerged and meristematic CRs (Table $1, P<0.01$ ). At 15 DAE, white lupin grown un- der P-deficient conditions developed 37 CRs (12 emerged and 25 meristematic), compared with 11 CRs (4 emerged and 7 meristematic) under P-sufficient conditions (Figure 4). Except for the number of meristematic CRs under P deficiency, NAA application greatly increased the number of CRs (Figure 4). It can be seen that $\mathrm{P}$ and auxin had a significant interactive effect on meristematic CRs (Table 1, $P<0.01)$. In the P-deficient treatment, NAA application increased the number of CRs by $19 \%$, whereas in the P-sufficient treatment NAA increased CR numbers by $154 \%$ (147\% for emerged CRs and $158 \%$ for meristematic CRs) (Figure 4). When TIBA was applied, the number of CRs was significantly reduced, with a decrease of $9 \%$ in P-sufficient and 65\% in P-deficient plants (Figure 4).

\subsection{Effects of $\mathbf{P}$ deficiency and auxin treatment on proton release, citrate exudation, and acid phosphatase activity}

The time course of proton release was examined daily throughout the experiment. The quantity of released protons increased slowly during the first 8 DAE. A relatively rapid rise in the number of released protons was observed there

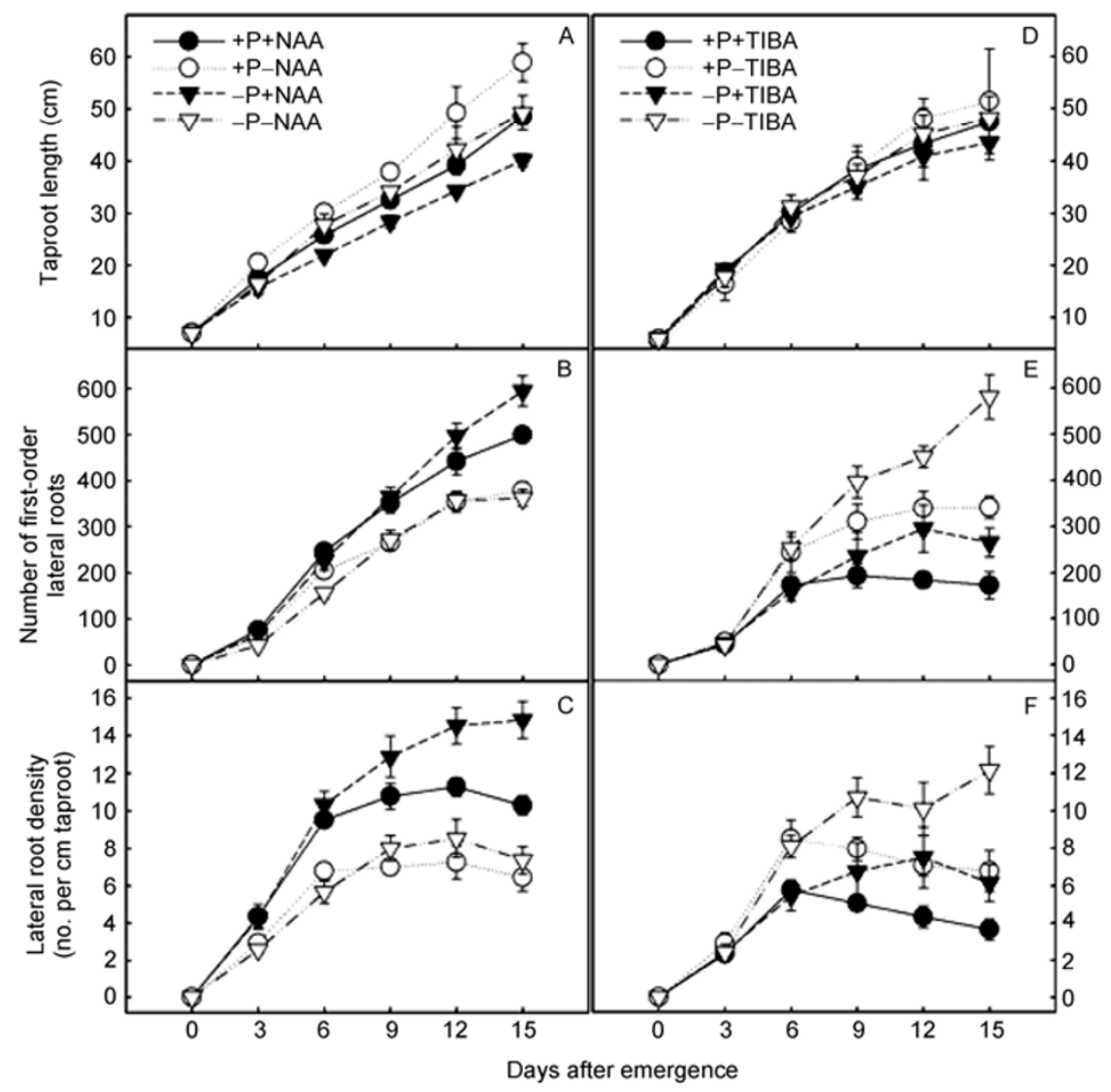

Figure 3 Effects of auxin and its transport inhibitor on taproot and lateral root development of white lupin under different $\mathrm{P}$ supply. Seedlings were grown in nutrient solution containing 0 or $250 \mu \mathrm{mol} \mathrm{L} \mathrm{L}^{-1} \mathrm{P}$ with or without the application of $10^{-8}$ mol $\mathrm{L}^{-1}$ NAA or TIBA. Data are given for the taproot length $(\mathrm{A}$ and D), the number of first-order lateral roots (LRs) (B and E), and lateral root density (C and F) at different growth stages. Values represent means \pm SE of four replicates. 
after in all treatments, except for a slight decrease in the P-sufficient treatment at 15 DAE (Figure 5). From 7 DAE onwards, P-deficient plants extruded more protons than P-sufficient ones $(P<0.05)$. The presence of auxin significantly increased proton release for P-deficient and P-sufficient plants $(P<0.05)$ from 10 DAE onwards (Figure $5)$. In addition, the rate of proton release was calculated based on average data from the final $3 \mathrm{~d}$ before harvest (Figure 5, inset). According to ANOVA, $\mathrm{P}$ and auxin had a significant influence on the proton release rate (Table 1 ,

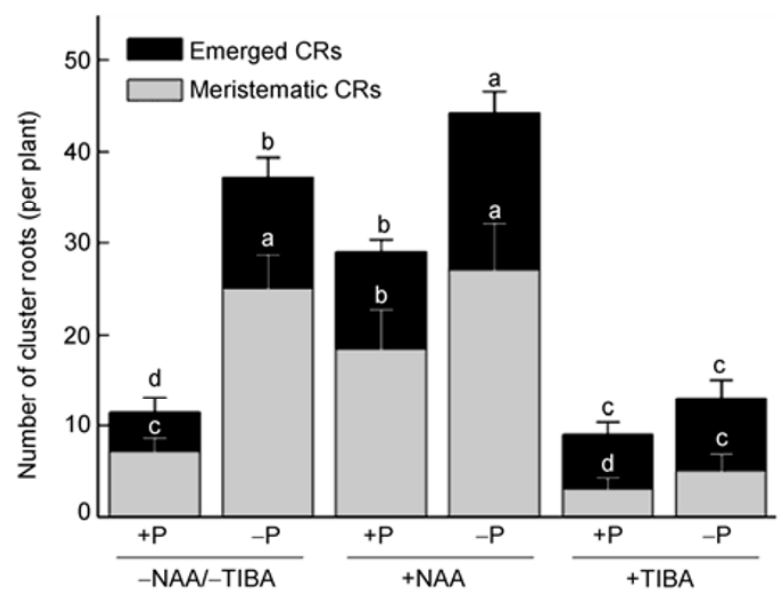

Figure 4 Effects of auxin and its transport inhibitor on CR formation in white lupin under different $\mathrm{P}$ supply. Seedlings were grown in 0 or 250 $\mu \mathrm{mol} \mathrm{L} \mathrm{L}^{-1} \mathrm{P}$ nutrient solutions with or without the application of $10^{-8}$ mol L ${ }^{-1}$ NAA or TIBA. Emerged CRs and meristematic CRs were defined as regions with 10 or more meristems or rootlets per cm of first-order lateral root. Data represent means $\pm \mathrm{SE}$ of four replicates. Different letters indicate significant differences among treatments for emerged or meristematic CRs $(P \leqslant 0.05)$.

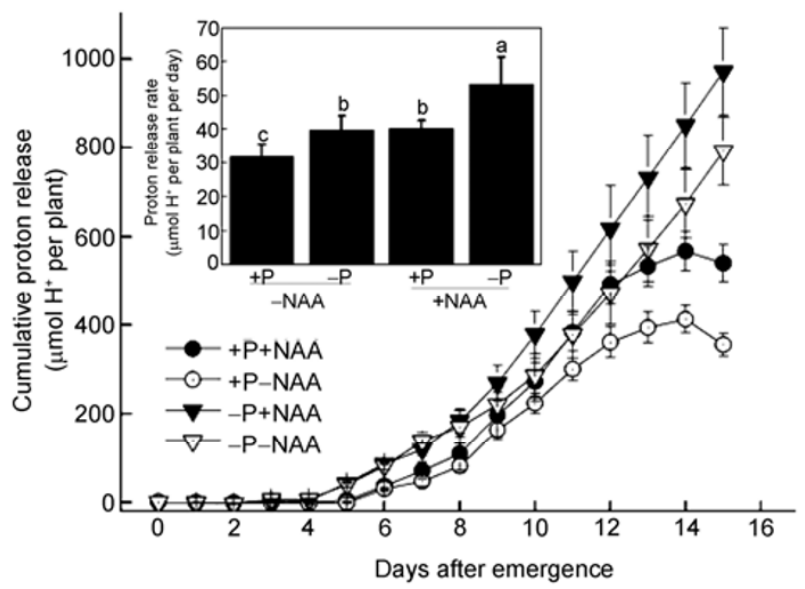

Figure 5 Effects of $\mathrm{P}$ availability and auxin addition on proton release in white lupin. Seedlings were cultured in 0 or $250 \mu \mathrm{mol} \mathrm{L}^{-1} \mathrm{P}$ nutrient solutions with or without the application of $10^{-8} \mathrm{~mol} \mathrm{~L}^{-1}$ NAA. Proton release was measured daily during the 15 -d growth period after emergence. The inset represents the effects of auxin addition on average proton release rates during the last $3 \mathrm{~d}$ before harvest. Data represent means $\pm S E$ of four replicates. Different letters indicate significant differences among treatments $(P \leqslant 0.05)$.
$P<0.01)$. A higher proton release rate was found in plants grown at $0 \mu \mathrm{mol} \mathrm{L}{ }^{-1} \mathrm{P}$ compared with those at $250 \mu \mathrm{mol} \mathrm{L} \mathrm{L}^{-1}$ $\mathrm{P}$, irrespective of auxin application. Auxin application increased proton release rates by $69 \%$ in P-sufficient plants and by $133 \%$ in P-deficient plants (Figure 5, inset).

To determine the effects of auxin on citrate exudation, root exudates were collected from entire root systems at 15 DAE. Two-way ANOVA revealed a significant effect of $P$ on citrate exudation of entire root systems. There was also an obvious interactive effect between $\mathrm{P}$ and auxin (Table 1). The rate of citrate exudation in P-deficient plants was 0.214 $\mu \mathrm{mol} \mathrm{g}^{-1}$ root dry weight $\mathrm{h}^{-1}$. When NAA was applied to P-deficient plants, a two-fold increase in the citrate exudation rate was observed compared with the treatment without NAA addition. In contrast, citrate exudation was not detected for P-sufficient plants, irrespective of NAA supply (Figure 6A). To further evaluate the contribution of auxin to citrate exudation, excised nonCRs and CRs from P-deficient and P-sufficient plants were treated with NAA for $2 \mathrm{~h}$. Phosphorus deficiency significantly increased citrate exudation rates in the excised CRs, with 4.7-5.2-fold higher increases observed compared with those from $\mathrm{P}$ sufficient plants. The application of NAA significantly increased cit-

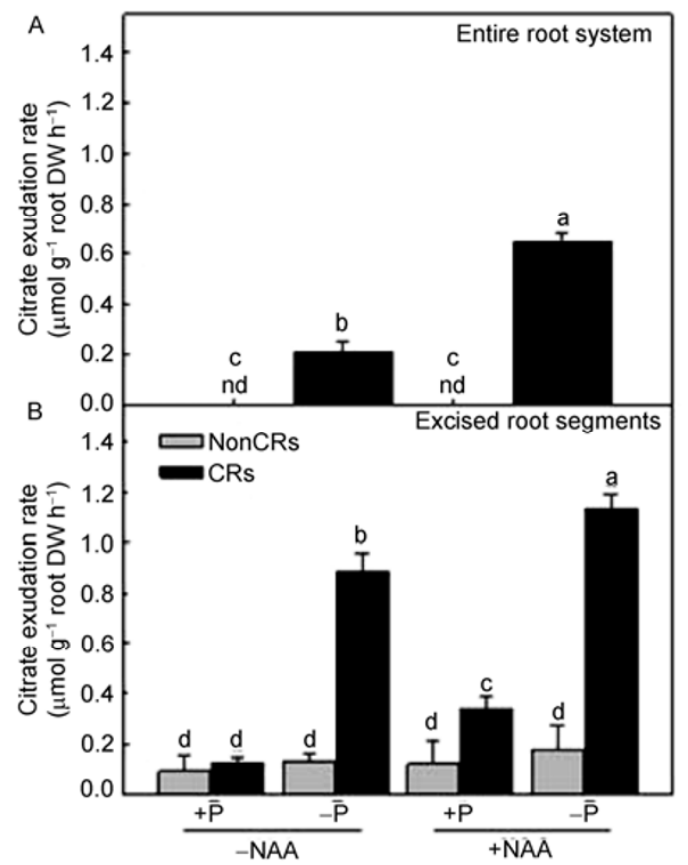

Figure 6 Effect of exogenous auxin addition on citrate exudation in P-sufficient and P-deficient white lupin. A, Citrate exudation by the entire root system. Seedlings were grown for $15 \mathrm{DAE}$ in 0 or $250 \mu \mathrm{mol} \mathrm{L} \mathrm{L}^{-1} \mathrm{P}$ nutrient solutions with or without the application of $10^{-8} \mathrm{~mol} \mathrm{~L}^{-1}$ NAA. Root exudates were collected for $2 \mathrm{~h}$ from intact root systems of individual plants. B, Citrate exudation by excised nonCRs and CRs of white lupin. Seedlings were grown for $15 \mathrm{DAE}$ in 0 or $250 \mu \mathrm{mol} \mathrm{L}{ }^{-1} \mathrm{P}$ nutrient solutions. NonCRs and CRs were excised and incubated in 0 or $10^{-8} \mathrm{~mol} \mathrm{~L}^{-1}$ NAA solutions with gentle agitation for $2 \mathrm{~h}$. After incubation, root exudates were collected and HPLC-analyzed for citrate. Values represent means $\pm \mathrm{SE}$ of four replicates. Different letters indicate significant differences among treatments ( $P \leqslant 0.05$; nd, not detected). 
rate exudation rates by $71 \%$ and $57 \%$ in $\mathrm{P}$-sufficient and P-deficient CRs, respectively (Figure 6B), suggesting a significant effect of $\mathrm{P}$ and auxin on citrate exudation of excised CRs (Table 1). In contrast, there was no significant difference in citrate exudation rates between nonCRs, regardless of $\mathrm{P}$ and auxin treatments (Table 1, Figure 6B).

Acid phosphatase activity in nonCRs and CRs was measured to examine the effects of $\mathrm{P}$ and auxin on such activity. Two-way ANOVA revealed a significant main effect of $\mathrm{P}$, and an interactive effect of $\mathrm{P}$ and auxin, on acid phosphatase activity in both nonCRs and CRs (Table 1). Regardless of auxin application, $\mathrm{P}$ deficiency increased acid phosphatase activity in both nonCRs and CRs (Figure 7). In P-deficient plants, but not in P-sufficient ones, CRs exhibited higher acid phosphatase activities than did nonCRs. In P-deficient plants, NAA addition also significantly increased acid phosphatase activity, with an increase of 37\%-39\% compared with control plants without NAA application. In P-sufficient plants, however, NAA addition had no effect on acid phosphatase activity in either CRs or nonCRs (Figure 7).

\subsection{Variation patterns and relative importance of root morphological and physiological traits as affected by $P$ deficiency and auxin addition}

The first two principal components from the PCA explained $86.1 \%$ of the total variation and significantly separated the four treatments (Figure 8A). PC1 (the first principal component) separated the four treatments into two groups based on $\mathrm{P}$ availability and explained $64.8 \%$ of the total variation; PC2 (the second principal component) separated the treatments into two groups based on auxin addition and ex-

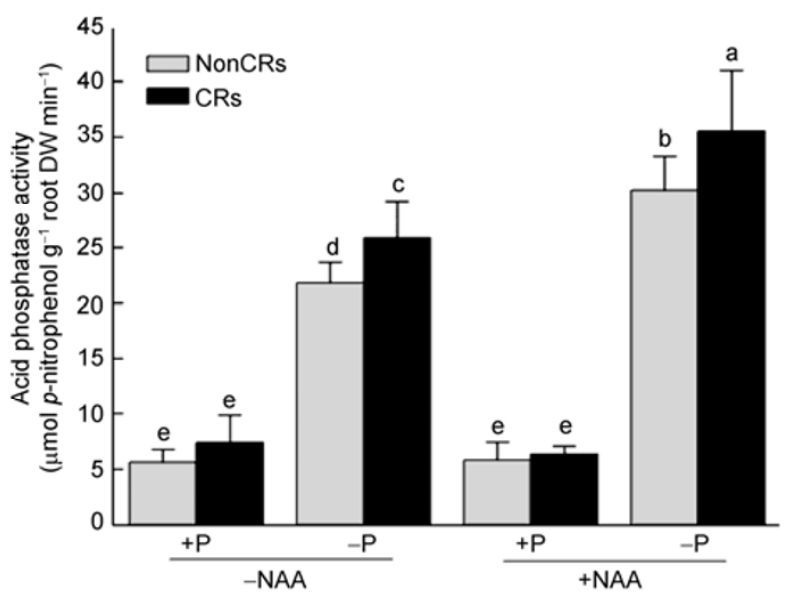

Figure 7 Effects of exogenous auxin addition on the activity of acid phosphatase excreted by nonCRs and CRs from P-sufficient and P-deficient white lupin. Seedlings were grown in 0 or $250 \mu \mathrm{mol} \mathrm{L}^{-1} \mathrm{P}$ nutrient solutions with or without the application of $10^{-8}$ mol L ${ }^{-1}$ NAA. At 15 DAE, plants were harvested and roots divided into nonCRs and CRs and subjected to acid phosphatase activity assays. Values represent means $\pm \mathrm{SE}$ of four replicates. Different letters indicate significant differences among treatments $(P \leqslant 0.05)$. plained $21.3 \%$ of the total variation. MANOVA showed that both $\mathrm{P}$ deficiency and auxin addition significantly affected root morphological and physiological traits (P: Hotelling's trace $=354, F=106, P<0.001$; Auxin: Hotelling's trace $=145$, $F=43.6, P<0.001$ ), and a significant interactive effect between $\mathrm{P}$ and auxin was also observed for root parameter variables (P×auxin: Hotelling's trace $=103, F=31.0, P<0.001$ ) (Table 2). Based on the PCA, P deficiency enhanced root morphological and physiological responses, but root physiological response was more important than root morphological response with respect to $\mathrm{P}$ acquisition (Figure $8 \mathrm{~B}$ ).

Table 2 Multivariate ANOVA for effects of $\mathrm{P}$ and auxin on root morphological and physiological parameters

\begin{tabular}{cccc}
\hline Sources of variation & Hotelling's trace & $F$-value & $P$-value \\
\hline P & 353.647 & 106.094 & $<0.001$ \\
Auxin & 145.274 & 43.582 & 0.005 \\
P×Auxin & 103.358 & 31.007 & 0.008 \\
\hline
\end{tabular}
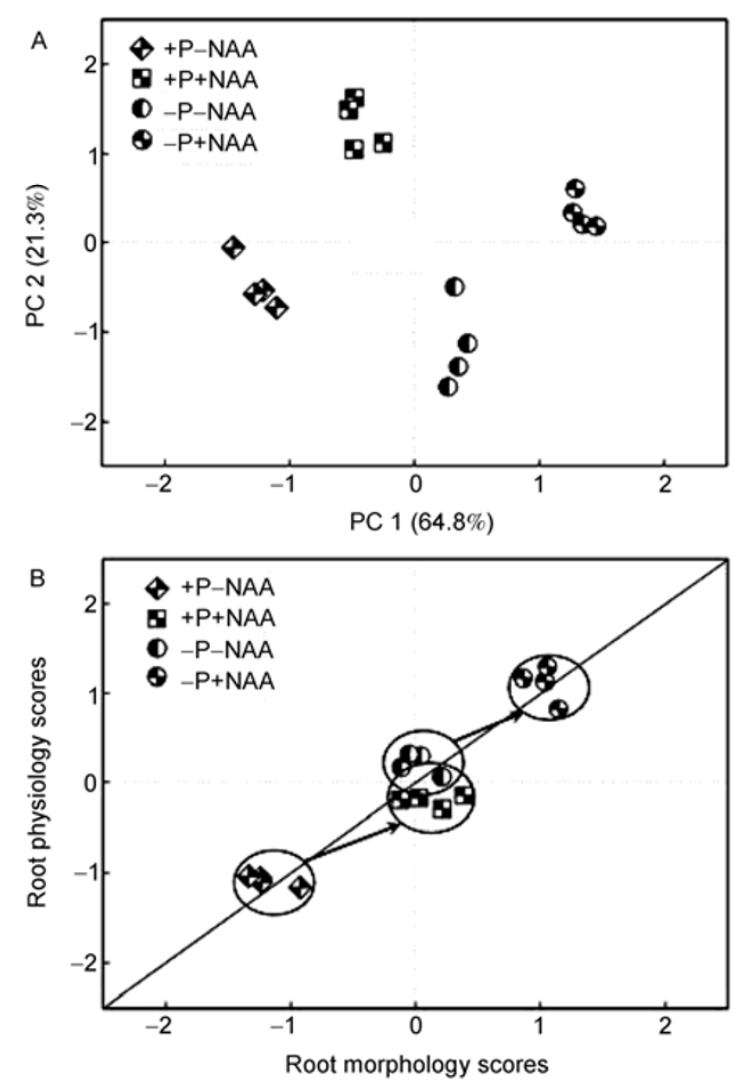

Figure 8 Variation patterns and relative importance of root morphological and physiological traits in response to $\mathrm{P}$ availability and auxin addition. A, 10 variables were subjected to PCA: the 5 root morphological traits of taproot length, number and density of the first-order lateral roots, and number of emerged and meristematic CRs and the 5 root physiological traits of proton release, citrate exudation by intact entire root systems and excised CRs, and acid phosphatase activity of nonCRs and CRs. B, Relative importance of root morphological and physiological traits. PCA was performed separately based on root morphological and physiological traits. Total scores of root morphological or physiological variables were calculated from the first two principal components. 
Auxin application changed the balance between root morphology and root physiology and caused an evident shift from root physiology to morphology for P-sufficient plants; this trade-off between root physiological and morphological traits was almost negligible under $\mathrm{P}$ deficiency, however, indicating the dominant role of $\mathrm{P}$ deficiency in changing both root physiological and morphological traits (Figure 8B).

\section{Discussion}

\subsection{Root morphological traits as affected by auxin in response to $P$ deficiency}

Plant roots exhibit a highly plastic response to environmental changes. Continuous initiation and emergence of new root meristems allows plants to acclimate to changes in $\mathrm{P}$ availability $[47,48]$. These plastic root responses are thought to assist in $\mathrm{P}$ acquisition by enhancing root foraging and uptake capacity $[28,49]$. In agreement with previous experimental studies $[15,35,37,47]$, our results indicate that $\mathrm{P}$ deficiency is a key factor controlling LR development (Figure 3) and CR formation (Figure 4). The mechanisms regulating lupin root system response to $\mathrm{P}$ deficiency are not fully understood, however.

Increasing evidence suggests that auxin plays a key role in the regulation of root morphology in response to P starvation [34-36,48,49]. In Arabidopsis, P deficiency leads to auxin redistribution and an increase in auxin sensitivity $[15,34,47,49]$. In white lupin, root-derived auxin plays a key role in $\mathrm{P}$ deficiency-induced $\mathrm{CR}$ formation [36]. In rice, exogenous auxin can amplify $\mathrm{P}$ starvation signaling [38], and a cross-talk exists between auxin and P starvation [39]. Application of exogenous auxin increases LR formation in Arabidopsis and CR proliferation in white lupin, whereas auxin antagonists reduce these effects $[35,36,50,51]$. These findings support the view that most effects of $\mathrm{P}$ deficiency on root morphological responses depend primarily on auxin signaling. In our study, auxin application reduced taproot length and stimulated LR formation and CR proliferation in both P-deficient and P-sufficient white lupin (Figures 3A-C and 4); however, application of TIBA eliminated these effects (Figures 3D-F and 4). It has been suggested that TIBA acts as a competitive inhibitor of auxin transport [52]. Our results showing TIBA significantly inhibiting LR and CR formation (Figures 3D-F and 4) are consistent with previous observations that TIBA can interfere with NAA activity $[15,35,36]$. Taken together, these results confirm that auxin plays an essential role in regulating root development of white lupin.

It is well known that CRs develop along the axis of first-order LRs and comprise relatively dense short rootlets [33]. CR formation consequently depends primarily on the production of first-order LRs. In our study, white lupin formed large numbers of CRs when more first-order LRs were produced under $\mathrm{P}$ deficiency or exogenous auxin supply. Auxin stimulated more LRs in P-deficient than P-sufficient plants (Figure 3B and C); this was not the case for CR formation (Figure 4), however, indicating a complex interplay between $\mathrm{P}$ and auxin during regulation of root development in white lupin. This result is consistent with a previous report in Arabidopsis that P-deprived seedlings, in terms of LRs, are more sensitive to auxin than are nondeprived seedlings [15]. A recent study revealed that an auxin receptor, TIR1 (TRANSPORT INHIBITOR RESPONSE1), may be responsible for regulation of auxin sensitivity to $\mathrm{P}$ deficiency. Under $\mathrm{P}$ deficiency, increased expression of TIR1, which mediates proteasome-involved degradation of AUX/IAA proteins, and hence increased LR production, is observed [34]. These results support the notion that $\mathrm{P}$ deficiency increases auxin sensitivity during LR formation in white lupin.

\subsection{Root physiological traits as affected by auxin in response to $P$ deficiency}

Root physiological responses are also important for nutrient acquisition [20]. Under P-deficient conditions, some plants, such as white lupin and common bean (Phaseolus vulgaris L.), release large amounts of carboxylates, acid phosphatase, and protons to mobilize and capture $\mathrm{P}$ from soils $[5,12,24]$. In our study, significantly increased proton release (Figure 5), citrate exudation (Figure 6), and acid phosphatase activity (Figure 7) were observed in P-deficient plants compared with P-sufficient ones. These results are in agreement with previous studies in maize (Zea mays L.) [53], common bean [24], white lupin [27-29,54], and purple lupin (L. pilosus Murr.) [5]. In contrast, $P$ deficiency did not increase proton release from soybean [55] or enhance secretion of organic acid anions from soybean [56,57] or rape (Brassica napus L.) [58]. These contradictory findings indicate that $\mathrm{P}$ deficiency-induced changes in root-exudation physiology are highly species-dependent.

Enhanced proton release under $\mathrm{P}$ deficiency is considered to be related to an increase in $\mathrm{PM} \mathrm{H}^{+}$-ATPase activity and stimulation of the $\mathrm{H}^{+}$-pump $[23,59,60]$. Increased citrate exudation from white lupin CRs has been correlated with increased efflux of $\mathrm{H}^{+}$[59] and other cations, including $\mathrm{K}^{+}$, $\mathrm{Na}^{+}$, and $\mathrm{Mg}^{2+}[27,61]$. Previous research indicates that the

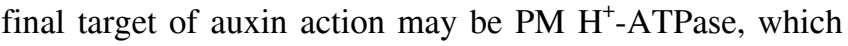
increases proton extrusion [41]. In our study, auxin enhanced proton release and citrate exudation regardless of $\mathrm{P}$ supply (Figures 5 and 6). It is possible that the enhanced citrate exudation observed under $\mathrm{P}$ deficiency and auxin was due to the stimulating effects of auxin on $\mathrm{H}^{+}$-ATPase activity. Further investigation is required, however, to elucidate the relationship between citrate exudation and $\mathrm{H}^{+}$-ATPase activity. Citrate efflux from white lupin CRs probably occurs through anion channels permeable to citrate $[30,62,63]$. The increased citrate exudation observed when 
auxin was applied in our study may be partly attributed to anion channel activation mediated by auxin $[64,65]$. Proton quantities extruded by $\mathrm{P}$ deficient plants are 2-3-fold greater than exuded citrate levels [66]. Because of the need to balance charges, proton extrusion under $\mathrm{P}$ deficiency is therefore related to increased citrate exudation. Under $\mathrm{P}$ deficiency in this study, the amount of proton release was positively correlated with, but higher than, the amount of citrate exuded $\left(Y=0.4042 X-8.3954, R^{2}=0.6137, P=0.0215\right)$. The stoichiometric ratio between proton release and citrate exudation was 3-9: 1 . The results presented here conform to previous findings that about half of proton extrusion can be attributed to citrate extrusion [66]. Taken together, these results suggest that proton extrusion induced by $\mathrm{P}$ deficiency or auxin application is closely associated with citrate exudation.

Increased acid phosphatase activity under P deficiency is well documented in white lupin and other species [24,67]. In a previous study of white lupin, acid phosphatase activity was greater in CRs of P-deficient plants than in nonCRs or in CRs of P-sufficient plants [54]. In our study, nonCRs and CRs of P-deficient plants had higher acid phosphatase activity than those of P-sufficient plants (Figure 7). This increased acid phosphatase activity may be related to $\mathrm{P}$ deficiency-induced apoplast acidification [68]. Apoplast acidification induced by $\mathrm{P}$ deficiency or auxin application may create optimal environmental conditions for maximizing extracellular acid phosphatase activity. These results indicate that $\mathrm{P}$ deficiency or auxin application-because of their

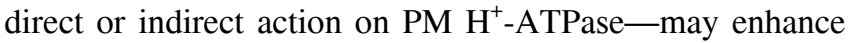
apoplast acidification due to stimulated proton release, and thus increase acid phosphatase activity.

\subsection{Relative importance of root morphological and physiological traits as affected by $P$ deficiency and auxin treatment}

Plant roots exhibit highly plastic responses to both temporal and spatial changes in resource availability [69]. The size and type of root plasticity are largely dependent on plant species [7,21], resource supply status [21], resource type and evenness [18,20,70], and competitor presence [71]. Some plant species present strongly plastic root responses to changes in the external environment [71,72], whereas others respond weakly [7]. As shown by PCA in our study, white lupin displays high root morphological and physiological plasticity in response to $\mathrm{P}$ availability and auxin application. Because $\mathrm{P}$ availability explained $64.8 \%$ and auxin addition represented $21.3 \%$ of the total variation, $\mathrm{P}$ was considered to be a more important factor than auxin for white lupin root plasticity (Figure 8A). The manner in which root development in white lupin is regulated by $\mathrm{P}$ and auxin is very complex, however. Auxin could mediate the processes in which P deficiency affects CR formation or root morphological plasticity. To unravel this complexity, the relative roles of $\mathrm{P}$ and auxin in regulating root morphological and physiological traits need to be further investigated.

Because of the complexity of root plasticity and the lack of comprehensive studies, it is difficult to quantify the extent and relative importance of root morphological and physiological effects [73]. A viewpoint can be proposed to explain the relative importance of root morphology and physiology for acquisition of limited resources. When resource distribution is size-asymmetrical, root morphological changes are more important than physiological ones. Alternatively when resource distribution is size-symmetrical, physiological changes are more important than morphological ones [74]. In soil, nutrient supply is unidirectional or distributed in a patchy manner [20], and root foraging for limited resources is size-asymmetrical; in such a situation, root morphological changes should be more important than physiological ones. In a hydroponic system where nutrient supply is multidirectional, root competition for limited resources should be size-symmetrical; in this case, physiological changes may be more important than morphological ones. Nevertheless, the extent and relative importance of root morphology and physiology is not fully understood. In our study, when white lupin was hydroponically grown under P deficiency or sufficiency, our results were consistent with the size-symmetrical hypothesis of limited resource acquisition. When exogenous auxin was added, however, the situation was greatly changed. Auxin addition differentially enhanced root morphological and physiological responses, thus changing the balance between root morphology and root physiology and emphasizing root morphology under sufficient $\mathrm{P}$ supply (Figure 8B). Our overall results suggest that variation patterns and relative importance of root morphology and physiology are highly dependent on the status of $\mathrm{P}$ and auxin supply and their interaction. Our study provides important evidence for the hypothesis that the relative importance of root morphology and physiology can be adjusted by $\mathrm{P}$ availability and auxin application in white lupin. The approach used in our study-examining relative importance or trade-off of root morphological and physiological traits - can be used to evaluate plant adaptation to environmental stress in other species.

In conclusion, $\mathrm{P}$ deficiency significantly affected both morphological and physiological traits of white lupin roots. Exogenous auxin significantly enhanced the sensitivity of root morphology to $\mathrm{P}$ deficiency. There was an evident interplay between $\mathrm{P}$ and auxin in modulating root morphological and physiological traits. In white lupin, $\mathrm{P}$ deficiency played a more important role than did exogenous auxin in regulating root morphological and physiological responses. Our results suggest that white lupin can effectively coordinate root morphological and physiological responses to enhance acquisition of $\mathrm{P}$ resources, with an optimal trade-off between root morphological and physiological traits governed by external stimuli such as $\mathrm{P}$ availability and auxin. 
This work was supported by the National Natural Science Foundation of China $(30925024,30890131,30871591)$, the Beijing Natural Science Foundation (6122021), the innovative group grant of NSFC (31121062), Ministry of Science and Technology of China (2013CB127402) and the Innovation Fund for Graduate Student of China Agricultural University (KYCX2011040).

1 Holford I C R. Soil phosphorus: its measurement, and its uptake by plant. Aust J Soil Res, 1997, 35: 227-239

2 Lin W Y, Lin S I, Chiou T J. Molecular regulators of phosphate homeostasis in plants. J Exp Bot, 2009, 60: 1427-1438

3 Schachtman D P, Reid R J, Ayling S M. Phosphorus uptake by plants: from soil to cell. Plant Physiol, 1998, 116: 447-453

4 Marschner H. Mineral Nutrition of Higher Plants, 2nd ed. London: Academic Press, 1995

5 Ligaba A, Shen H, Shibata K, et al. The role of phosphorus in aluminium-induced citrate and malate exudation from rape (Brassica napus). Physiol Plantarum, 2004, 120: 575-584

6 Vance C P, Uhde-Stone C, Allan D L. Phosphorus acquisition and use: critical adaptations by plants for securing a nonrenewable resource. New Phytol, 2003, 157: 423-447

7 Fransen B, Blijjenberg J, de Kroon H. Root morphological and physiological plasticity of perennial grass species and the exploitation of spatial and temporal heterogeneous nutrient patches. Plant Soil, 1999, 211: $179-189$

8 Ericsson T. Growth and shoot-root ratio of seedlings in relation to nutrient availability. Plant Soil, 1995, 168: 205-214

9 Hermans C, Hammond J P, White P J, et al. How do plants respond to nutrient shortage by biomass allocation? Trends Plant Sci, 2006, 11: $610-617$

10 Lynch J P, Ho M D. Rhizoeconomics: carbon costs of phosphorus acquisition. Plant Soil, 2005, 269: 45-56

11 Nielsen K L, Eshel A, Lynch J P. The effect of phosphorus availability on the carbon economy of contrasting common bean (Phaseolus vulgaris L.) genotypes. J Exp Bot, 2001, 52: 329-339

12 Pang J Y, Ryan M H, Tibbett M, et al. Variation in morphological and physiological parameters in herbaceous perennial legumes in response to phosphorus supply. Plant Soil, 2010, 331: 241-255

13 Bates T R, Lynch J P. Stimulation of root hair elongation in Arabidopsis thaliana by low phosphorus availability. Plant Cell Environ, 1996, 19: 529-538

14 Zhu J M, Zhang C C, Lynch J P. The utility of phenotypic plasticity of root hair length for phosphorus acquisition. Funct Plant Biol, 2010, 37: $313-322$

15 López-Bucio J, Hernandez-Abreu E, Sanchez-Calderon L, et al. Phosphate availability alters architecture and causes changes in hormone sensitivity in the Arabidopsis root system. Plant Physiol, 2002, 129: 244-256

16 Casper B B, Jackson R B. Plant competition underground. Annu Rev Ecol Syst, 1997, 28: 545-570

17 He Y, Liao H, Yan X L. Localized supply of phosphorus induces root morphological and architectural changes of rice in split and stratified soil cultures. Plant Soil, 2003, 248: 247-256

18 Jing J, Rui Y, Zhang F, et al. Localized application of phosphorus and ammonium improves growth of maize seedlings by stimulating root proliferation and rhizosphere acidification. Field Crop Res, 2010, 119: $355-364$

19 Li H G, Shen J B, Zhang F S, et al. Localized application of soil organic matter shifts distribution of cluster roots of white lupin in the soil profile due to localized release of phosphorus. Ann Bot-London, 2010, 105: 585-593

20 Hodge A. The plastic plant: root responses to heterogeneous supplies of nutrients. New Phytol, 2004, 162: 9-24

21 Jackson R B, Manwaring J H, Caldwell M M. Rapid physiological adjustment of roots to localized soil enrichment. Nature, 1990, 344: $58-60$

22 Neumann G, Martinoia E. Cluster roots-an underground adaptation for survival in extreme environments. Trends Plant Sci, 2002, 7:
162-167

23 Shen $\mathrm{H}$, Chen J H, Wang Z Y, et al. Root plasma membrane $\mathrm{H}^{+}$-ATPase is involved in the adaptation of soybean to phosphorus starvation. J Exp Bot, 2006, 57: 1353-1362

24 Kouas S, Debez A, Slatni T, et al. Root proliferation, proton efflux, and acid phosphatase activity in common bean (Phaseolus vulgaris) under phosphorus shortage. J Plant Biol, 2009, 52: 395-402

25 Lamont B B. Structure, ecology and physiology of root clusters-a review. Plant Soil, 2003, 248: 1-19

26 Hocking P J, Jeffery S. Cluster-root production and organic anion exudation in a group of old-world lupins and a new-world lupin. Plant Soil, 2004, 258: 135-150

27 Shen J, Li H, Neumann G, et al. Nutrient uptake, cluster root formation and exudation of protons and citrate in Lupinus albus as affected by localized supply of phosphorus in a split-root system. Plant Sci, 2005, 168: 837-845

28 Lambers H, Shane M W, Cramer M D, et al. Root structure and functioning for efficient acquisition of phosphorus: matching morphological and physiological traits. Ann Bot-London, 2006, 98: 693-713

29 Wang B L, Tang X Y, Cheng L Y, et al. Nitric oxide is involved in phosphorus deficiency-induced cluster-root development and citrate exudation in white lupin. New Phytol, 2010, 187: 1112-1123

30 Neumann G, Römheld V. Root excretion of carboxylic acids and protons in phosphorus-deficient plants. Plant Soil, 1999, 211: 121130

31 Neumann G, Massonneau A, Martinoia E, et al. Physiological adaptations to phosphorus deficiency during proteoid root development in white lupin. Planta, 1999, 208: 373-382

32 Tomasi N, Kretzschmar T, Espen L, et al. Plasma membrane $\mathrm{H}^{+}$-ATPase-dependent citrate exudation from cluster roots of phosphate-deficient white lupin. Plant Cell Environ, 2009, 32: 465-475

33 Dinkelaker B, Hengeler C, Marschner H. Distribution and function of proteoid roots and other root clusters. Bot Acta, 1995, 108: 183-200

34 Pérez-Torres C A, López-Bucio J, Cruz-Ramírez A, et al. Phosphate availability alters lateral root development in Arabidopsis by modulating auxin sensitivity via a mechanism involving the TIR1 auxin receptor. Plant Cell, 2008, 20: 3258-3272

35 Gilbert G A, Knight J D, Vance C P, et al. Proteoid root development of phosphorus deficient lupin is mimicked by auxin and phosphonate. Ann Bot-London, 2000, 85: 921-928

36 Meng Z B, You X D, Suo D, et al. Root-derived auxin contributes to the phosphorus-deficiency-induced cluster-root formation in white lupin (Lupinus albus). Physiol Plantarum, 2012, doi: 10.1111/ j.1399-3054.2012.01715.x

37 Neumann G, Massonneau A, Langlade N, et al. Physiological aspects of cluster root function and development in phosphorus-deficient white lupin (Lupinus albus L.). Ann Bot-London, 2000, 85: 909-919

38 Hou X L, Wu P, Jiao F C, et al. Regulation of the expression of OsIPS1 and OsIPS2 in rice via systemic and local Pi signalling and hormones. Plant Cell Environ, 2005, 28: 353-364

39 Shen C, Wang S, Zhang S, et al. OsARF16, a transcription factor, is required for auxin and phosphate starvation response in rice (Oryza sativa L.). Plant Cell Environ, 2012, 36: 607-620

40 Rober-Kleber N, Albrechtova J T P, Fleig S, et al. Plasma membrane $\mathrm{H}^{+}$-ATPase is involved in auxin-mediated cell elongation during wheat embryo development. Plant Physiol, 2003, 131: 1302-1312

41 Hager A. Role of the plasma membrane $\mathrm{H}^{+}$-ATPase in auxin-induced elongation growth: historical and new aspects. J Plant Res, 2003, 116: 483-505

42 Skene K R. Cluster roots: model experimental tools for key biological problems. J Exp Bot, 2001, 52: 479-485

43 Johnson J F, Vance C P, Allan D L. Phosphorus deficiency in Lupinus albus - altered lateral root development and enhanced expression of phosphoenolpyruvate carboxylase. Plant Physiol, 1996, 112: 31-41

44 Tang C, Barton L, Raphael C. Pasture legume species differ in their capacity to acidify soil. Aust J Agr Res, 1998, 49: 53-58

45 Westerman R L. Soil Testing and Plant Analysis. 3rd ed. Madison: Soil Science Society of America, 1990 
46 Neumann G. Quantitative determination of acid phosphatase activity in the rhizosphere and on the root surface. In: Luster J, Finlay R, eds. Handbook of Methods Used in Rhizosphere Research. Online Edition, 2006

47 Malamy J E, Ryan K S. Environmental regulation of lateral root initiation in Arabidopsis. Plant Physiol, 2001, 127: 899-909

48 Williamson L C, Ribrioux S P C P, Fitter A H, et al. Phosphate availability regulates root system architecture in Arabidopsis. Plant Physiol, 2001, 126: 875-882

49 Nacry P, Canivenc G, Muller B, et al. A role for auxin redistribution in the responses of the root system architecture to phosphate starvation in Arabidopsis. Plant Physiol, 2005, 138: 2061-2074

50 Casimiro I, Marchant A, Bhalerao R P, et al. Auxin transport promotes Arabidopsis lateral root initiation. Plant Cell, 2001, 13: 843-852

51 Reed R C, Brady S R, Muday G K. Inhibition of auxin movement from the shoot into the root inhibits lateral root development in Arabidopsis. Plant Physiol, 1998, 118: 1369-1378

52 Katekar G F, Geissler A E. Auxin transport inhibitors. 4. evidence of a common-mode of action for a proposed class of auxin transport inhibitors - the phytotropins. Plant Physiol, 1980, 66: 1190-1195

53 Gaume A, Machler F, De Leon C, et al. Low-P tolerance by maize (Zea mays L.) genotypes: significance of root growth, and organic acids and acid phosphatase root exudation. Plant Soil, 2001, 228: 253-264

54 Gilbert G A, Knight J D, Vance C P, et al. Acid phosphatase activity in phosphorus-deficient white lupin roots. Plant Cell Environ, 1999, 22: $801-810$

55 Tang C, Han X Z, Qiao Y F, et al. Phosphorus deficiency does not enhance proton release by roots of soybean [Glycine max (L.) Murr.]. Environ Exp Bot, 2009, 67: 228-234

56 Tang C, Qiao Y F, Han X Z, et al. Genotypic variation in phosphorus utilisation of soybean [Glycine $\max (\mathrm{L}$.) Murr.] grown in various sparingly soluble P sources. Aust J Agr Res, 2007, 58: 443-451

57 Yang Z M, Sivaguru M, Horst W J, et al. Aluminium tolerance is achieved by exudation of citric acid from roots of soybean (Glycine max). Physiol Plantarum, 2000, 110: 72-77

58 Ligaba A, Yamaguchi M, Shen H, et al. Phosphorus deficiency enhances plasma membrane $\mathrm{H}^{+}$-ATPase activity and citrate exudation in greater purple lupin (Lupinus pilosus). Funct Plant Biol, 2004, 31: 1075-1083

59 Yan F, Zhu Y Y, Müller C, et al. Adaptation of $\mathrm{H}^{+}$-pumping and plasma membrane $\mathrm{H}^{+}$-ATPase activity in proteoid roots of white lupin under phosphate deficiency. Plant Physiol, 2002, 129: 50-63

60 Zandonadi D B, Santos M P, Dobbss L B, et al. Nitric oxide mediates humic acids-induced root development and plasma membrane $\mathrm{H}^{+}$-ATPase activation. Planta, 2010, 231: 1025-1036

61 Zhu Y Y, Yan F, Zorb C, et al. A link between citrate and proton release by proteoid roots of white lupin (Lupinus albus L.) grown under phosphorus-deficient conditions? Plant Cell Physiol, 2005, 46: 892-901

62 Zhang W H, Ryan P R, Tyerman S D. Citrate-permeable channels in the plasma membrane of cluster roots from white lupin. Plant Physiol, 2004, 136: 3771-3783

63 Wang B, Shen J, Zhang W, et al. Citrate exudation from white lupin induced by phosphorus deficiency differs from that induced by aluminum. New Phytol, 2007, 176: 581-589

64 Thomine S, Lelièvre F, Boufflet $\mathrm{M}$, et al. Anion-channel blockers interfere with auxin responses in dark-grown Arabidopsis hypocotyls. Plant Physiol, 1997, 115: 533-542

65 Diatloff E, Roberts M, Sanders D, et al. Characterization of anion channels in the plasma membrane of Arabidopsis epidermal root cells and the identification of a citrate-permeable channel induced by phosphate starvation. Plant Physiol, 2004, 136: 4136-4149

66 Sas L, Rengel Z, Tang C. Excess cation uptake, and extrusion of protons and organic acid anions by Lupinus albus under phosphorus deficiency. Plant Sci, 2001, 160: 1191-1198

67 Tadano T, Ozawa K, Sakai H, et al. Secretion of acid-phosphatase by the roots of crop plants under phosphorus-deficient conditions and some properties of the enzyme secreted by lupin roots. Plant Soil, 1993, 155: 95-98

68 Hayes J E, Richardson A E, Simpson R J. Phytase and acid phosphatase activities in extracts from roots of temperate pasture grass and legume seedlings. Aust J Plant Physiol, 1999, 26: 801-809

69 Novoplansky A. Picking battles wisely: plant behaviour under competition. Plant Cell Environ, 2009, 32: 726-741

70 Yano K, Kume T. Root morphological plasticity for heterogeneous phosphorus supply in Zea mays L. Plant Prod Sci, 2005, 8: 427-432

71 Semchenko M, John E A, Hutchings M J. Effects of physical connection and genetic identity of neighbouring ramets on root-placement patterns in two clonal species. New Phytol, 2007, 176: 644-654

72 Cahill J F, McNickle G G, Haag J J, et al. Plants integrate information about nutrients and neighbors. Science, 2010, 328: 1657-1657

73 Schwinning S, Weiner J. Mechanisms determining the degree of size asymmetry in competition among plants. Oecologia, 1998, 113: 447-455

74 Grams T E E, Andersen C P. Competition for resources in trees: physiological versus morphological plasticity. In: Esser K, Lüttge U, Beyschlag E, eds. Progress in Botany. Heidelberg: Springer-Verlag, 2007

Open Access This article is distributed under the terms of the Creative Commons Attribution License which permits any use, distribution, and reproduction in any medium, provided the original author(s) and source are credited. 